\title{
A COMPARATIVE STUDY BETWEEN LOSS ON IGNITION AND TOTAL CARBON ANALYSIS ON MINEROGENIC SEDIMENTS
}

\author{
DANIEL Ș. VEREȘ
}

\begin{abstract}
The present study deals with a comparison between organic and carbonate content determinations based on loss-on-ignition and step-wise total carbon analysis, and a correlation to grain-size. Although loss-on-ignition can generally be regarded as an accurate measure of the organic mater content of a sediment, the amount of fine fraction in the sediments is a limiting factor for an absolute organic determination and influences directly the correction factor. The same holds true for carbonate content determinations based on loss on ignition. In order to provide accurate organic and carbonate content determinations for a sediment, loss-on-ignition data must be corroborated by standard total carbon analysis.
\end{abstract}

Keywords: minerogenic sediments, loss-on-ignition, total carbon, Late Glacial, Atteköps mosse, Sweden.

\section{Introduction}

The sedimentological properties of lacustrine sediments can provide valuable data on the nature of former depositional environments, being useful indices of climatic and other local and regional environmental changes (Lowe \& Walker, 1997).

A common way to generate a rough sediment geochemistry profile is to use the loss-on-ignition method. Numerous authors from Dean (1974) and onwards have noted that this method can be considered to be a good tool for determining the organic matter and carbonate contents of sediments, even if several uncertainties limit the absolute precision of the method (Dean, 1974; Bengtsson \& Enell, 1986; Heiri et al., 2001). The relative changes of loss-onignition parameters throughout the analyzed core sections were regarded as very useful in interpreting the impact of changing climatic conditions on different biogeochemical processes throughout the sediment sequence, and often are sufficient for correlation between overlapping-cores.

On the other hand, total carbon determined automatically is the fundamental parameter for describing the abundance of organic and inorganic carbon in sediments. In this way, an organic matter value, via loss-on-ignition, are, presumed to be equivalent to about twice the total organic carbon values

${ }^{1}$ Quaternary Research Group, Dept. of Mineralogy, Babeș-Bolyai University, Kogălniceanu 1, 3400 Cluj, Romania. 
(Meyers \& Lallier-Vergés, 1999). Total organic carbon can be both diluted by clastic sediment particles and concentrated by dissolution of carbonate minerals.

The present paper presents results of several sedimentological analyses performed upon the deepest, minerogenic core segment ( $1 \mathrm{~m}$ long), taken on the Atteköps mosse, southwestern Sweden. The study site, which is located in Hallandsåsen area, is considered, alongside by Kullen Peninsula (Sandgren et al., 1999) one of the earlier deglaciated region in Sweden.

Therefore, the aim of this study is to assess the usefulness of the losson-ignition method in estimating the organic and carbonate contents in minerogenic sediments. The assumption is that the method over-estimates the organic matter and carbonate content of fine-grained sediments because of a weight loss related to various organic and inorganic sediment components. Total carbon analysis with a specific carbon analyzer is generally viewed to be a better indicator for those parameters. To test this hypothesis, conventional loss-on-ignition analysis, total carbon and grain-size measurements were performed over selected sediment intervals and compared with each other.

\section{Introduction to the methods}

\section{Loss-on-ignition}

Loss-on-ignition is a common and widely used method to estimate sediment properties (i.e., water content, organic matter, inorganic carbon and minerogenic residue), because is the quickest and cheapest among all the methods employed for determining some of those parameters (Dean, 1974; Maher, 1998).

Most sediment is composed of a mixture of clastic silicates and oxides (sand, silt and clay fractions), organic material, carbonates and water. Quantitative determinations of such sediment parameters by means of loss-on-ignition are based on the sequential heating of the samples (other techniques involve gas collecting and measuring the amount either volumetrically or chromatically (Dean, 1974)) in a muffle furnace (Heiri et al., 2001). After oven drying of the sediment to constant weight (or dry matter) and cooling to room temperature, organic matter is combusted in a first reaction to ash and carbon dioxide at temperatures between $500-550^{\circ} \mathrm{C}$. The amount of organic matter is the weight difference between the dry sediment and the $550^{\circ} \mathrm{C}$ ash (Dean, 1974; Maher, 1998; Heiri et al., 2001), being assumed to be derived from organic material with the formula $\left(\mathrm{CH}_{2} \mathrm{O}\right)_{n}$, (Snowball \& Sandgren, 1996).

In a second step, the same sample is ignited at temperatures of $925^{\circ} \mathrm{C}$ (Bengtsson \& Enell, 1986, Heiri et al., 2001) or $1000^{\circ} \mathrm{C}$ (Dean, 1974; Maher, 1998) in order to find the amount of carbon dioxide evolved from the breakdown of the carbonate minerals. The carbonate content in the original sample is then determined by multiplying the weight loss between loss-on-ignition at $550^{\circ} \mathrm{C}$ and loss-on-ignition at $925^{\circ} \mathrm{C}$ with 1.36 , which is the ratio between the molecular weights of $\mathrm{CO}_{3}(60)$ and $\mathrm{CO}_{2}(44)$, according to Bengtsson \& Enell (1986). 
Dean (1974) and Bengtsson \& Enell (1986) pointed out that the method is fast and inexpensive and thus useful for analyses of a large number of samples. It also gives a rough indication of the organic matter and carbonate contents and a good correlation with organic carbon content, despite of several uncertainties (see the Discussions chapter), which limit the precision of the method.

\section{Grain-size distribution}

Particle size distribution is a fundamental property of sedimentary material and can be used to infer the provenance and history of the sediment transport (Buckley \& Cranston, 1991).

Size analysis of clay and silt-sized sediment can be inferred by a variety of automated methods based on their physical, electrical and optical properties. The Sedigraph method used by this study, measures the sedimentation speed of suspended particles by monitoring the rate at which particles settle and are removed from the monitored volume, giving in that way a cumulative size distribution of the sediments (Coakley \& Syvitski, 1991).

\section{Total carbon}

Total carbon concentration is a fundamental parameter for describing the abundance of organic matter and inorganic carbon in sediments (Meyers \& Lallier-Vergés, 1999).

The total organic carbon concentration is a bulk value that represents the fraction of organic matter that escaped mineralization during sedimentation processes being influenced by both initial biomass production and subsequent degree of degradation. Total organic carbon concentration often varies through the sedimentary sequence, indicating changes in organic deposition under different sedimentary conditions (Meyers \& Lallier-Vergés, 1999).

\section{Samples and analysis}

\section{Core collection and description}

Multiple core segments were retrieved with a Russian peat sampler $(1 \mathrm{~m}$ length and $10 \mathrm{~cm}$ diameter). The lithostratigraphy of the cores was described both in the field and in the laboratory (see the description in Table 1).

Because detailed sedimentological analyses mainly focused on the minerogenic sediments, only the lowest segment $(\mathrm{C} 6-\mathrm{a}, 767-690 \mathrm{~cm})$ of core C6 was selected for further analysis in this study.

\section{Sediment analysis}

For loss-on-ignition analysis, volumetrically samples were weighed (using a Sartorius-Tillquist model $\mathrm{H} 120$ balance), placed in pre-weighted crucibles and dried for $12 \mathrm{~h}$ at $105^{\circ} \mathrm{C}$ (using a Termarks oven) to determine both the water content (or loss-on-drying) and dry sediment percentages (normally 3-5 g), the latter serving as a base to which ignition losses were compared. 
The weight loss during the ignitions (using a Heraeus type 170 muffle furnace) were calculated according to Bengtsson \& Enell's (1986) formula, with the exception that in the present study the weight loss is related to dry weight. Samples were gradually heated until they reached temperatures of $550^{\circ} \mathrm{C}$ and $925^{\circ} \mathrm{C}$, respectively and afterwards ignited for $4 \mathrm{~h}$ at the respective temperatures. The samples were then put into a desiccator and weighed at room temperatures. The carbonate content was determined by multiplying the weight loss obtained between $550^{\circ} \mathrm{C}$ and $925^{\circ} \mathrm{C}$ with 1.36 .

For the grain-size analysis a Micromeritics Sedigraph 5100 Particle Size Analysis System was used. This sedigraph uses a collimated beam of $X$-rays to sense the sedimentation speed of suspended particles with time and a device measurement of particles with diameters ranging from 100 to 0,2 micrometers (Coackley \& Syvitski, 1991). The samples $\left(2-3 \mathrm{~cm}^{3}\right)$ were first split to obtain a subsample of approximately $1.8 \mathrm{~g}$ for analysis, deflocculated in $40 \mathrm{ml} \mathrm{Na}_{4} \mathrm{P}_{2} \mathrm{O}_{7}$ and dispersed by means of ultrasonic stirring. Because it had been noted that samples with high organic carbon $(>10 \%)$ can hinder proper dispersion of the sample (see Coakley \& Syvitski, 1991), selected intervals were used where organic matter content was low. Finally, the grain size distribution data is presented as cumulative percentages of several fractions: clay $(<2 \mu \mathrm{m})$, fine silt $(2-6 \mu \mathrm{m})$, medium silt $(6-20 \mu \mathrm{m})$, coarse silt $(20-60 \mu \mathrm{m})$ and fine sand $(60-100 \mu \mathrm{m})$.

The organic and inorganic carbon content of the selected samples was determined by temperature-controlled combustion in pure oxygen (step-wise heating from 100 to $1000^{\circ} \mathrm{C}$ ) of the homogenous and dried samples with subsequent detection of carbon dioxide by infrared absorption photometry in a LECO RC 412 Multiphase Carbon Determinator. The sediments were dried (for $12 \mathrm{~h}$ at $105^{\circ} \mathrm{C}$ ), finely ground and homogenized and then stirred and shaken in a tungsten ball container. Due to different amounts of material available, sample size varied between 0.12 and $0.30 \mathrm{~g}$ of dry weight. The carbon emitted between 105 and $650^{\circ} \mathrm{C}$ is interpreted as the content of organic carbon of the samples, otherwise, the carbon evolved between 650 and $925^{\circ} \mathrm{C}$ is interpreted as the carbonate content, assuming theoretical carbon contents of $12 \%$ and $c$. $40 \%$ for pure calcium carbonate and organic matter, respectively.

\section{Results and discussion}

\section{Lithostratigraphy}

The nature of sediment sequence analyzed by this study is shown in Table 1. Organic and carbonate contents for core C6-a estimated using both loss-on-ignition and total carbon analyses, are presented in Figures 1 and 3 . The results of grain-size distribution analysis are summarized in Figure 4 (right). The relationship between sediment geochemical parameters and granulometry is also shown in Figure 4. 
Table 1.

Lithostratigraphic units and sediment description for Core C6-a.

\begin{tabular}{|c|c|c|c|}
\hline Unit & Layer & $\begin{array}{l}\text { Depth below } \\
\text { surface }(\mathrm{cm})\end{array}$ & Sediment description \\
\hline VI & 15 & $667-679$ & Beige grey silt gyttja. \\
\hline & 14 & $679-685$ & Beige grey gyttja silt sparse in FeS stains. UB-rg. \\
\hline & 13 & $685-692$ & $\begin{array}{l}\text { Beige grey clayey silt gyttja, with cladocera remains. UB-rg. } \\
685-688 \mathrm{~cm} \text { more beige, } \\
688-692 \mathrm{~cm} \text { more dark. }\end{array}$ \\
\hline $\mathbf{V}$ & 12 & $692-715$ & $\begin{array}{l}\text { Beige grey clayey silt gyttja, brown in moss rich areas, } \\
\text { laminated by some organic matter layers. UB-rg. } \\
696-700 \mathrm{~cm} \text { some moss remains, } \\
700-704,5 \mathrm{~cm} \text { increase in moss remains, } \\
704,5-707 \mathrm{~cm} \text { few moss remains, } \\
707-708 \mathrm{~cm} \text { brown layer, rich in mosses. }\end{array}$ \\
\hline IV & 11 & $715-720$ & $\begin{array}{l}\text { Brown to beige-grey clayey gyttja silt, organic matter } \\
\text { decreases gradually upwards to } 718 \mathrm{~cm} \text {. UB-fs. }\end{array}$ \\
\hline \multirow{7}{*}{ III } & 10 & $720-722$ & Very disturbed layer of light grey silt, UB-fs. \\
\hline & 9 & $722-724$ & Dark grey coarse sand/gravels. UB-fs. \\
\hline & 8 & $724-732$ & $\begin{array}{l}\text { Dark grey clayey silt with some coarse silt in the bottom. } \\
\text { UB-s. }\end{array}$ \\
\hline & 7 & 732-733,5 & $\begin{array}{l}\text { Beige grey clayey silt layer, abundant mosses, laminations. } \\
\text { UB-fs. }\end{array}$ \\
\hline & 6 & $733,5-734$ & Light grey silt layer with some moss remains. UB-rg. \\
\hline & 5 & $734-739,5$ & Dark grey clayey silt with mosses $(736-737 \mathrm{~cm})$. UB-fs. \\
\hline & 4 & $739,5-741$ & $\begin{array}{l}\text { Grey silt with coarse silt and organic material in the } \\
\text { bottommost part (dark grey). UB-g. }\end{array}$ \\
\hline \multirow[t]{2}{*}{ II } & 3 & $741-754$ & $\begin{array}{l}\text { Dark grey silty clay laminated by thin silt-layers; gravel } \\
\text { particles at } 745 \text { and } 748 \mathrm{~cm} \text {, respectively. UB-fs. }\end{array}$ \\
\hline & 2 & $754-757$ & $\begin{array}{l}\text { Layers of dark-grey to black silty clay laminated every } 0,5 \\
\mathrm{~cm} \text {; calcareous particles. UB-fs. }\end{array}$ \\
\hline $\mathbf{I}$ & 1 & $757-767$ & $\begin{array}{l}\text { Grey fine-sand to sand with thin silt lamination; calcareous } \\
\text { particles and vague lamination from coarse silt to fine } \\
\text { sand. UB-rg. }\end{array}$ \\
\hline
\end{tabular}

\section{Comparison between loss-on-ignition and total carbon}

The accuracy of organic matter determination by means of loss-onignition seems to be hampered by some factors, which limit the precision of the method, leading to an overestimation of the true organic content. It was generally noted that for determining organic carbon content of minerogenic sediments by means of organic matter (via loss-on-ignition), the results can strongly be overestimated because of various losses, which belong to volatile salts, organic compounds (e.g. Bengtsson \& Enell, 1986), structural water (e.g. Dean, 1974), sulphide oxidation (Ramrath et al., 1999) or inorganic carbon. For example, if 
inorganic carbon is present it will evolve $\mathrm{CO}_{2}$ at temperatures between 425 and $520^{\circ} \mathrm{C}$ in minerals such magnesite, rhodochrosite (Heiri et al., 2001) or siderite (Hedvall, 1925, cited by Hammarlund, 1994). Moreover, as Aaby (1983, cited by Andersen, 1986) pointed out, the volume of organic matter cannot be determined exactly, as pore space enters the volume of the ignitable matter. In this case, changes in the organic content can be detected by determination of organic carbon (Andersen, 1986). On the other hand, technical factors such as sample size, exposure time, position of the sample in the furnace may affect the losson-ignition results, with loss on ignition at $550^{\circ} \mathrm{C}$ being more susceptible to these factors than loss-on-ignition at $925^{\circ} \mathrm{C}$. As a consequence, any bias of loss-on-ignition at $550^{\circ} \mathrm{C}$ will influence the results of loss-on-ignition at $925^{\circ} \mathrm{C}$ (Heiri et al., 2001).

In general, the amount of organic matter determined by loss-on-ignition at $550^{\circ} \mathrm{C}$ is considered to be "approximately" twice the organic carbon content (Dean, 1974, 1999; Snowball \& Sandgren, 1996) of a sample. Although this converting is generally accepted and widely used, various conversion factors have been proposed for converting organic carbon to original organic matter content of a sample. For example, Dean (1974) found a conversion factor of 2.13, Zolitschka \& Löhr (1999, cited by Ramrath et al., 1999) and Ramrath et al., (1999) have proposed a factor of 1.82 and 1.81, respectively, while Digerfeldt et al. (2000) obtained a factor of 1.45 .

One of the major goals of this study is to test the accuracy of organic carbon determination by loss-on-ignition, since selected values from loss on ignition at $550^{\circ} \mathrm{C}$ are believed to represent either typically organic matter, but also a weight loss related to various organic or inorganic sediment components. Therefore, organic carbon values determined automatically and on the same sample are regarded as representative for the organic carbon of the original sediment matter, and are compared to corresponding loss on ignition values. The results of this test are plotted in Figure 1 (left panel). Surprisingly, the resulting regression line crosses the $y$-axis at a loss-on-ignition value of $1.06 \%$. This probably corresponds to a weight loss, which should be related to the already mentioned extra-loss generators. The true organic matter content in the analyzed samples as suggested by the equation presented in Figure 1 (left) may be obtained by multiplication of the total organic carbon determined automatically with a factor of 1.49 . Though this low factor suggests a good correlation between these different organic carbon determinations, indicating that loss-on-ignition is a rather accurate measurement of the amount of organic matter in a sample, the resulting conversion factor is not in good agreement with the published factors presented above. This confirms the idea that the amplitude in difference between the results of those two methods may depend on type and chemical composition of the analyzed sediments.

In order to test the accuracy of the organic matter determination and to find out a proper correction factor (making abstraction by the factor determined by this study), the ignition loss results were compared with total organic carbon 

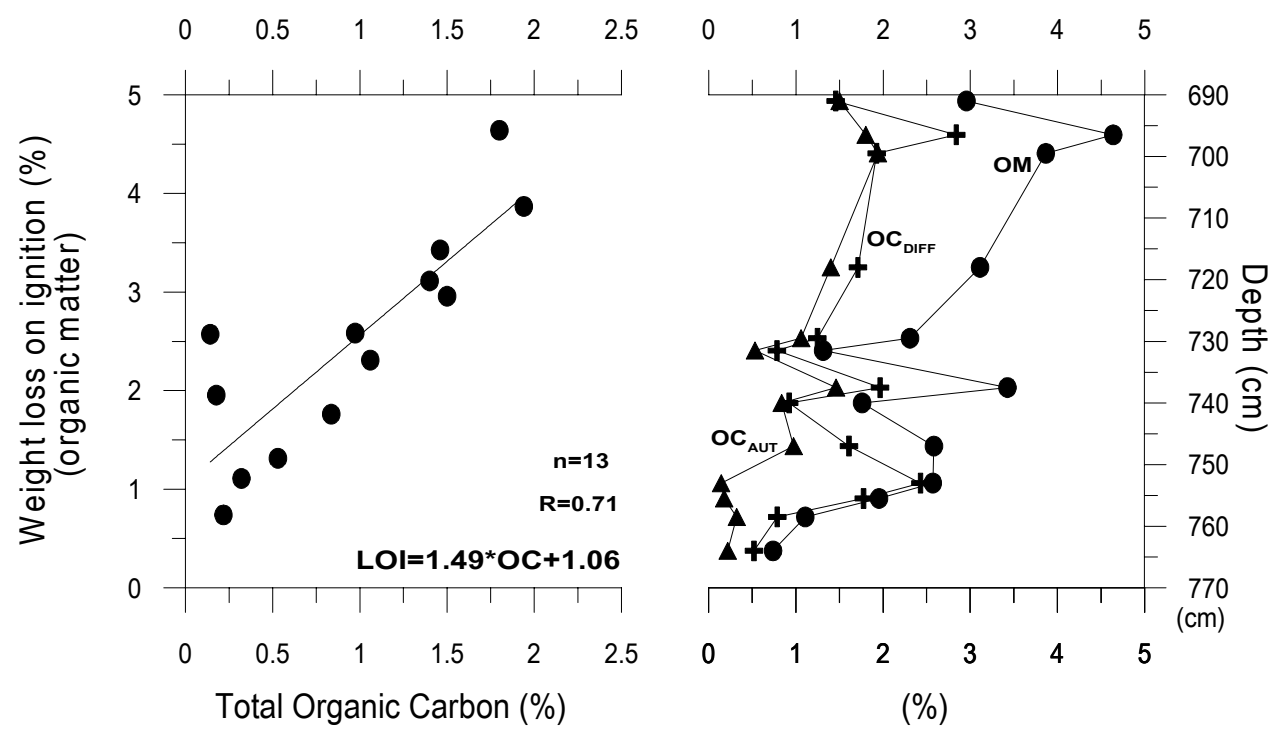

Figure 1. Left: Scatter diagram of percent total organic carbon determined automatically and percent organic matter at $550{ }^{\circ} \mathrm{C}$ measured on samples from Atteköps mosse. Number of data points (n), correlation coefficient $(R)$ and the regression line are given.

Right: Percentage organic carbon determined automatically $\left(O C_{A U T}\right.$-triangles), percentage organic matter (OM $\mathrm{LO}_{\mathrm{LO}}$-circles), and the difference in results between those parameters (OC DIFF-crosses), plotted against depth.

multiplied by different conversion factors (Fig. 2, left panel):

- $\mathrm{A}_{1}$ - automatically determined organic carbon multiplied by 2.5 (according to the chemical formula $\mathrm{CH}_{2} \mathrm{O} / \mathrm{C}$ )

- $\mathrm{B}_{1}$ - automatically determined organic carbon multiplied by 2.13 (according to Dean, 1974)

- $\mathrm{C}_{1}$ - automatically determined organic carbon multiplied by 1.82 (Zolitschka \& Löhr, 1999 cited by Ramrath et al., 1999)

- $\mathrm{D}_{1}$ - automatically determined organic carbon multiplied by 1.81 (Ramrath et al., 1999)

- $\mathrm{E}_{1}$ - automatically determined organic carbon multiplied by 1.45 (Digerfeldt et al., 2000).

The variables that resulted as differences between loss-on-ignition at $550^{\circ} \mathrm{C}$ and organic carbon multiplied by different constants are labeled from $A_{2}$ (as a variable produced by the $A_{1}$-chemical formula) to $E_{2}$ (a variable induced by the $E_{1}$ - Digerfeldt et al., 2000) and plotted in Figure 2 (right). The vertical zero line implies a perfect correlation between the values. The positive trend suggests that the loss-on-ignition values at $550^{\circ} \mathrm{C}$ are higher than presumably supposed, while the negative values, indicating higher values for organic carbon. 
As easily may be seen from the curves in Figure 2 (right), the $A_{2}$ and $B_{2}$ variables yield generally negative values, implying in this way an overestimation of primary organic matter content determined by loss-on-ignition. The $C_{2}$ and $D_{2}$ variables are relatively close to zero, whereas $E_{2}$ leads to increased differences. To summarize these results, it is evident that the conversion factors mentioned above are strongly influenced by the type of sediment analyzed.

Moreover, if an absolute determination of the organic content is to be done, then the loss-on-ignition data must be supported by independent total organic carbon determination.

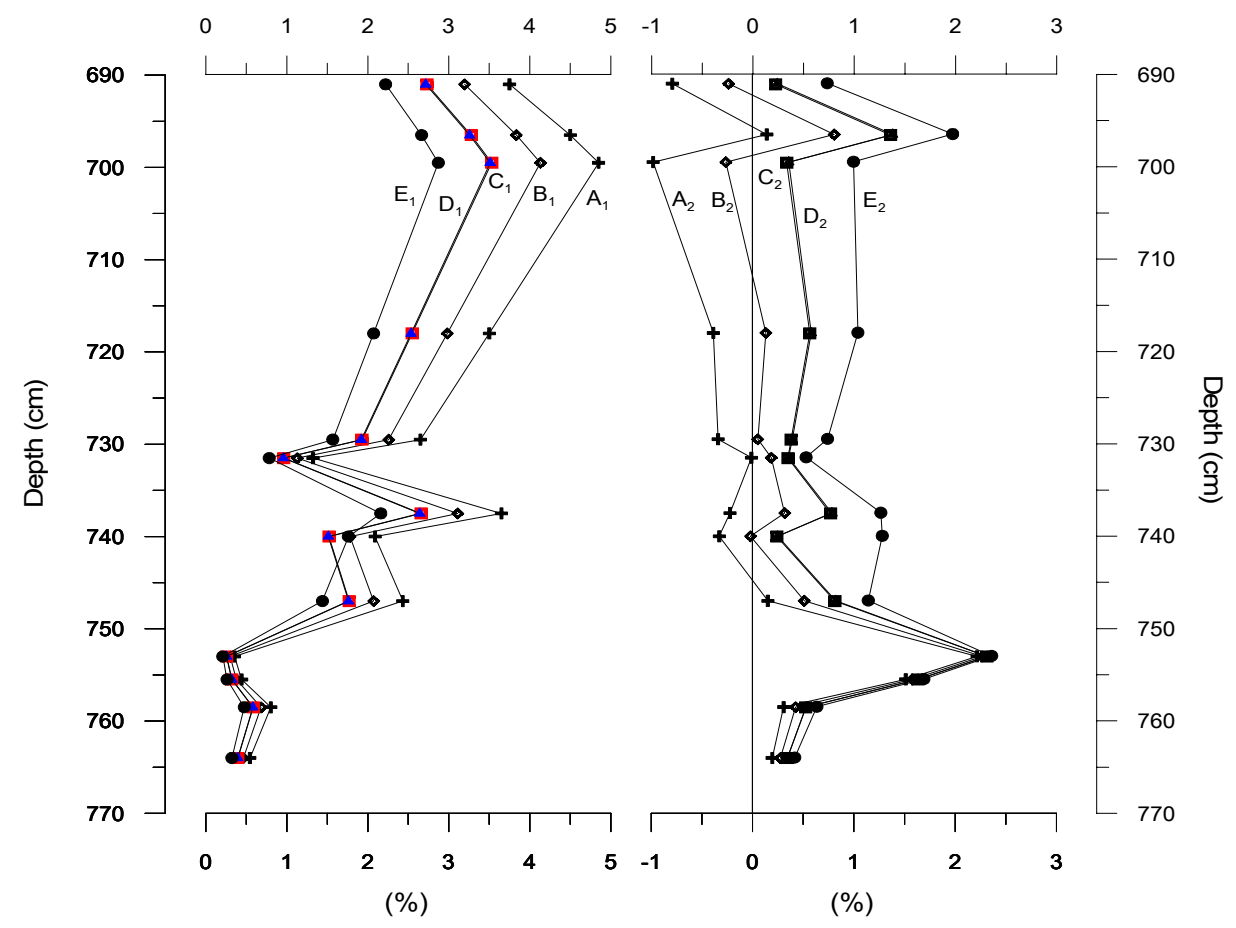

Figure 2. Left: Organic carbon determined automatically and multiplied by various conversion factors: 2.5 ( $A_{1}$-crosses), 2.13 ( $B_{1}$-rhombus), 1.82 ( $C_{1}$-triangles), 1.81 ( $D_{1}$-squares) and 1.45 ( $E_{1}$-circles) plotted against depth.

Right: The differences $\left(A_{2}, B_{2}, C_{2}, D_{2}, E_{2}\right)$, which result from a subtraction of organic carbon determined automatically and multiplied by the already mentioned factors from loss on ignition at $550^{\circ} \mathrm{C}$.

The main difference between the two methods is shown by the curves presented in Figure 3. Thus, if the carbonate content determined automatically $\left(\mathrm{CC}_{\mathrm{AUT}}\right)$ in an order of $<2 \%$ is viewed as the proper carbonate content of the analyzed sediments, then the high carbonate percentages $(<7 \%)$ derived from loss-on-ignition at $925^{\circ} \mathrm{C}\left(\mathrm{CC}_{\mathrm{LOI}}\right)$ lead to a large difference $\left(\mathrm{CC}_{\mathrm{DIF}}\right)$ between those two methods (for further discussions see Fig. 4). 

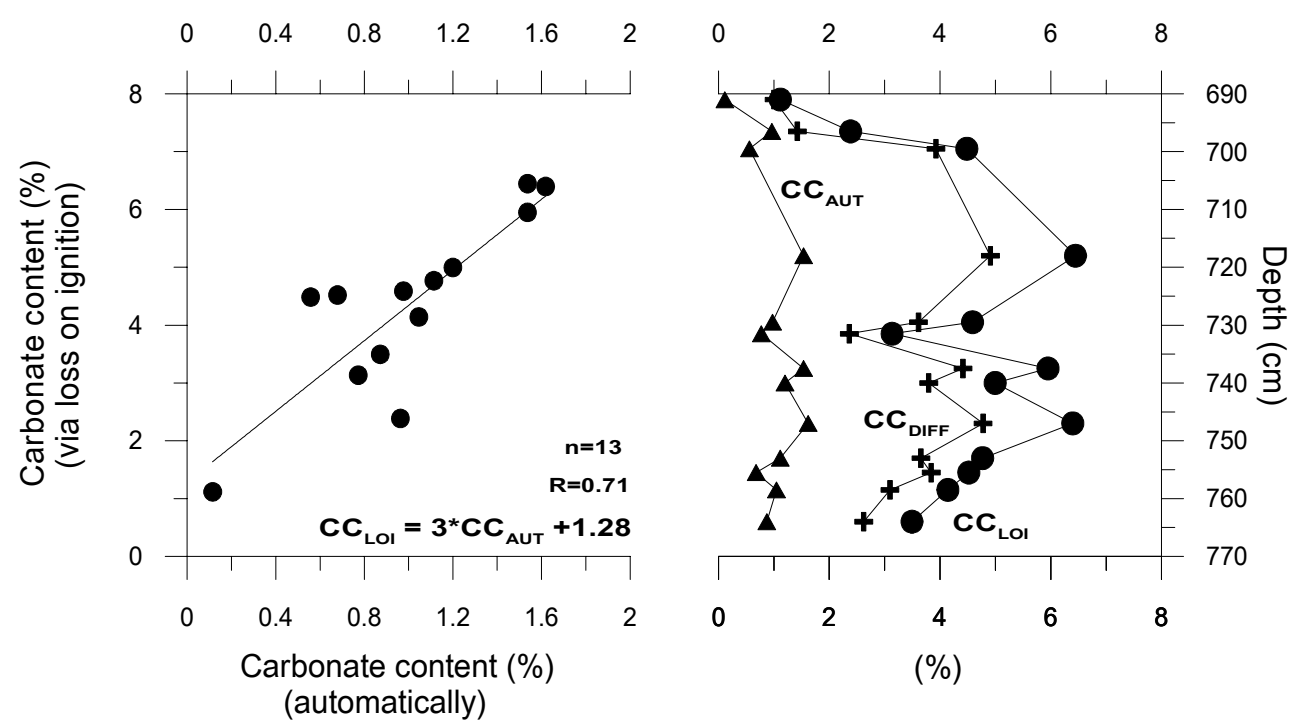

Figure 3. Left: Scatter diagram of percent carbonate content determined automatically and percent carbonate content derived from loss-on-ignition at $925^{\circ} \mathrm{C}$ measured on samples from Atteköps mosse. 1.36 multiplies both values. Number of data points $(n)$, correlation coefficient $(R)$ and the regression line are given.

Right: Selected values of carbonate carbon determined automatically $\left(C C_{A U T}\right.$-fill triangles), carbonate content calculated from loss-on-ignition at $925{ }^{\circ} \mathrm{C}$ (CC $\mathrm{Cor}_{\mathrm{LO}}$-fill circles) and the difference in results between those parameters $\left(C^{C} C_{D I F F}\right)$ plotted against depth. 1.36 multiplies both carbonate contents.

In order to check the assumption that higher percentages of organic carbon are commonly associated with fine-grained sediments, because of the higher adsorption capacities of finer particles, the above discussed differences between loss-on-ignition and total carbon (see Fig. 4-left) were related to grain size data at the corresponding levels (Fig. 4-right). It is known that clays may contain up to $5 \%$ hydroxyl groups $(\mathrm{OH})^{-}$as structural water. If a fine fraction is present in relatively high quantity, but has low carbonate content, those hydroxyl groups should be liberated as water when the sample is heated up over $550^{\circ} \mathrm{C}$. In this way, part of the loss $(4-5 \%)$, may result from that chemically bound water loss in such samples with high clay and low carbonate content (Maher, 1998). Thereby, the assumption that the ignition loss between 550$925^{\circ} \mathrm{C}$ represents $\mathrm{CO}_{2}$ evolved from carbonates will be in error by an amount, which is directly proportional to the amount of clay present, and inversely proportional to the amount of carbonates present (see Dean, 1974).

It is evident from Figure 4 (left) that the $\mathrm{OC}_{\mathrm{DIFF}}$ curve has more or less the same trend as the curve for the finer fraction. The difference is not so large because the clay fraction is only around $20-30 \%$ (compared with $50-70 \%$ in Digerfeldt et al., 2000). For example, Ramrath et al., (1999) and Digerfeldt et al., (2000) found a weight loss related to the above-mentioned loss generators of $5.3 \%$ and $7.8 \%$, respectively, whereas in this study the weight loss is $1.06 \%$. 


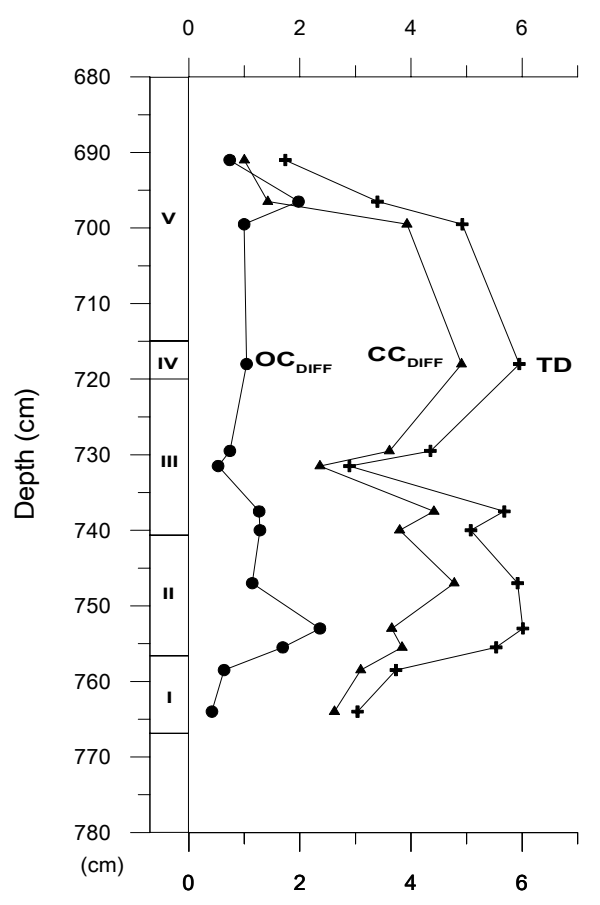

(\%)

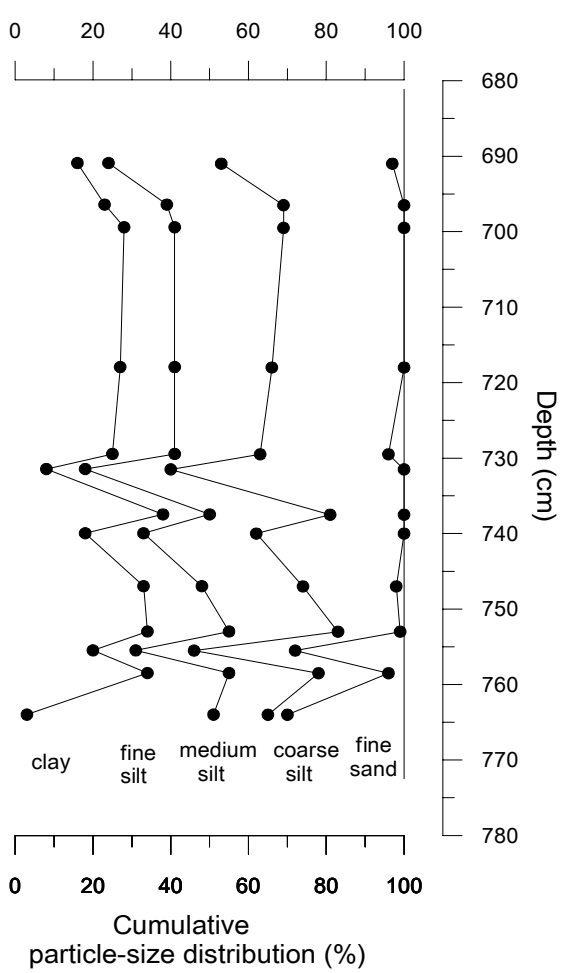

Figure 4. Left: Organic carbon difference $\left(O C_{D I F F}\right.$-circles), carbonate content difference ( $C C_{D I F F}$-triangles) and total difference (TD-crosses). $T D=O C_{D I F F}+C C_{D I F F} ;$

Right: Cumulative particle size distribution (\%) for selected values.

The most evident correlation between the variable features and the grain-size distribution is suggested by the $C_{\text {DIFF }}$ curve. It is obvious that a rise in clay content leads to a difference between the methods. This seems to be valid for fine silt as well. For example, in the lower most sample, where the clay content is extremely low and fine silt dominates the grain-size distribution, the $\mathrm{CC}_{\text {DIFF }}$ is in an order of $\sim 3 \%$. The coarse fraction (medium silt, coarse silt and fine sand) has generally the same trend as the finer fraction and seems not to influence the amplitude of the difference, at least, not as much as the fine fraction.

Total difference (TD) is a composite curve combining the values of both variables presented above. It increases where the fine fraction is high.

\section{Concluding remarks}

- Loss-on-ignition is an accurate measurement of primary organic content of sediments, if the fine fraction is present in low percentages.

- Sediment composition seems to be the main cause, which determines the value of correction factor between loss-on-ignition and total organic carbon. If an absolute organic carbon determination is to be done, losson-ignition data must be sustained by organic carbon determination. 
- Carbonate carbon determination by means of loss-on-ignition is strongly influenced by the distribution of the fine fraction. A rise in clay content is closely followed by a rise in extra weight-loss. Care must be taken in the interpretation of carbonate content via loss-on-ignition as a paleoenvironmental indicator.

\section{Acknowledgments}

This article is an excerpt of "Examensarbete $i$ geologi vid universitetKvartärgeologi, nr 145, 2001" Master Thesis, which was initiated while doing my master thesis at Lund University, Sweden. I gratefully acknowledge the support from Barbara Wohlfarth and Svante Björck who were my supervisors.

\section{REFERENCES}

Andersen, S. T. (1986): Palaeoecological studies of terrestrial soils. In B. E. Berglund (Ed): Handbook of Holocene Palaeoecology and Palaeohydrology. Wiley, Chichester, 165-177.

Bengtsson, L. \& Enell, M. (1986): Chemical analysis. In B.E. Berglund (Ed): Handbook of Holocene Palaeoecology and Palaeohydrology, Wiley, Chichester, 423-445 p.

Buckley, D. E., \& Cranston, R. E. (1991): The use of grain size information in marine geochemistry. In J. P. M. Syvitski (Ed): Principles, Methods and Application of Particle Size Analysis.

Coakley, J. P., \& Syvitski, J. P. M. (1991): Sedigraph technique. In J.P.M. Syvitski (Ed): Principles, Methods and Application of Particle Size Analysis.

Dean, W. E. Jr. (1974): Determination of carbonate and organic matter in calcareous sediments and sedimentary rocks by loss on ignition: Comparison with other methods. Journal of Sedimentary Petrology, 44, 242-248 p.

Dean, W. E. Jr. (1999): The carbon cycle and biogeochemical dynamics in lake sediments. Journal of Paleolimnology, 21, 375-393 $p$.

Digerfeldt, G., Olsson, S. and Sandgren, P. (2000): Reconstruction of lake-level changes in lake Xinias, central Greece, during the last 40000 years. Palaeogeography, Palaeoclimatology, Palaeoecology ,158, 65-82 p.

Hammarlund, D. (1994): Stable carbon and oxygen isotopes studies of Late Weichselian lake sediments in southern Sweden and northern Poland, with palaeoclimatic implications. Lundqua Thesis, 31, $30 p+4$ app.

Heiri, O., Lotter A. F. and Lemcke, G. (2001): Loss-on-ignition as a method for estimating organic and carbonate content in sediments: reproducibility and comparability of results. Journal of Paleolimnology, 25, 101-110 p. 
DANIEL Ș. VEREȘ

Lowe, J.J \& Walker, M.J.C. (1997): Reconstructing Quaternary Environments. Second edition, Longman Limited, $446 \mathrm{p}$.

Maher, L. J. Jr. (1998): Automating the dreary measurements for loss on ignition. INQUA Sub-Commission on Data-Handling Methods, newsletter 18.

Meyers, P. A. \& Lallier-Vergès, E. (1999): Lacustrine sedimentary organic matter of Late Quaternary paleoclimates. Journal of Paleolimnology, 21, 345-372 p.

Ramrath, A., Zolitschka, B., Wulf, S. and Negendank, J. F. W. (1999): Late Pleistocene climatic variations as recorded in two italian maar lakes (Lago di Mezzano, Lago grande di Montichio). Quaternary Science Reviews, 18, 977-992 p.

Sandgren, P., Snowball, I. F., Risberg, J. and Hammarlund, D. (1999): Stratigraphic evidence of a high marine shore-line during the Late Weichselian deglaciation on the Kullen Peninsula, southern Sweden. Journal of Quaternary Science, 14, 223-237 p.

Snowball, J. \& Sandgren, P. (1996): Lake sediment studies of Holocene glacier activity in the Kårsa valley, northern Sweden: contrast in interpretation. The Holocene, 6, 367$372 \mathrm{p}$. 